Title: The effect of rolling contact fatigue mitigation measures on wheel wear and rail fatigue

Ulrich Spangenberg, corresponding author, research were conducted at this affiliation

Affiliation: Mechanical Technology, Transnet Freight Rail \& Vehicle Dynamics Group, Department of Mechanical and Aeronautical Engineering University of Pretoria

Postal address: Private Bag X637, 0001, Pretoria, South Africa

Telephone number: +27 123348709

Email: ulrich.spangenberg@transnet.net

Robert Desmond Fröhling

Affiliation: Mechanical Technology, Transnet Freight Rail

Postal address: Private Bag X637, 0001, Pretoria, South Africa

Telephone number: +27 123348707

Email: robert.frohling@transnet.net

Pieter Schalk Els

Affiliation: Vehicle Dynamics Group, Department of Mechanical and Aeronautical Engineering University of Pretoria

Postal address: Private Bag X20, Hatfield, 0028, Pretoria, South Africa

Telephone number: + 27124202045

Email: schalk.els@up.ac.za 


\title{
The effect of rolling contact fatigue mitigation measures on wheel wear and rail fatigue
}

\author{
U. Spangenberg ${ }^{\mathrm{a}, b^{*}}$, R.D. Fröhling ${ }^{\mathrm{a}}$ and P.S. Els ${ }^{\mathrm{b}}$ \\ ${ }^{a}$ Mechanical Technology, Transnet Freight Rail, Pretoria, Gauteng, South Africa; \\ ${ }^{b}$ Vehicle Dynamics Group, University of Pretoria, Pretoria, Gauteng, South Africa
}

\begin{abstract}
The maintenance costs associated with heavy haul operations are mainly driven by wheel and rail damage in the form of wear and rolling contact fatigue (RCF). RCF initiated on the surface of the rail is the dominant damage mode on South Africa's iron ore export line. Two potential rail RCF mitigation measures were adapted from service tests and those published in literature and studied. The mitigation measures involved changes in suspension stiffness in an attempt to spread wheel wear across the tread and changes in rail profile design. These mitigation measures were evaluated by means of multi-body dynamics simulations including wheel wear predictions. Changes in suspension stiffness and rail profile design caused concentrated hollow wear on the wheels. These worn shapes of the wheels are conducive to RCF initiation with the worst performance coming from the application of a rail profile with gauge corner relief. Contact between the gauge side false flange of the wheel and the relief section of the rail profile were shown to increase the probability of RCF initiation.
\end{abstract}

\section{Keywords:}

Wheel-rail interface, wear modelling, rolling contact fatigue, self-steering bogie design, anti-head check rail profiles

\section{INTRODUCTION}

Heavy haul freight railways are designed to transport huge volumes of freight at high axle loads over long distances and at a lower cost than other modes of transport. However, heavy haul operations experience challenges with wheel, rail, track and bogie maintenance. The wheel-rail interface is thus a key component in determining cost-efficiency [1]. Wheel and rail wear are inevitable consequence of the rolling-sliding contact within this interface. If this interface is maintained well and functions optimally, it will result in proper vehicle guidance, low frictional forces, low operational cost and adequate safety.

South Africa has two heavy haul freight lines, the coal export line and the iron ore export line. The $861 \mathrm{~km}$ iron ore export line is one of the world's longest heavy haul lines, operates the longest production heavy haul trains and is loaded to 30 tons per axle. Currently rolling contact fatigue (RCF) damage is the predominant rail damage mode on this line. RCF damage is experienced on the gauge corner of high rails and field side of low rails.

On the South African iron ore export line, a self-steering, high stability freight bogie has been used since April 1976 [2]. This bogie was designed to counter unacceptably high flange wear rates [3]. The reduction in wheel flange wear achieved by this bogie together with relatively straight track, rail grinding and tighter gauge control led to the concentration of wheel wear in the centre of the wheel tread. Wheel flange wear became less of a concern and the predominant damage mode changed from wear damage to RCF damage. The progression from the wear regime, where rail side wear and wheel flange wear is dominant, to the stress regime, where RCF is dominant, has been discussed by Tournay and Mulder [4]. RCF develops due to contact between the so-called false flanges of the hollow worn wheels and the gauge corner and field side of the rails $[5,6]$. The adverse contact conditions resulting from the false flanges are shown in Figure 1.

\footnotetext{
${ }^{*}$ Corresponding author. Email: ulrich.spangenberg@transnet.net
} 


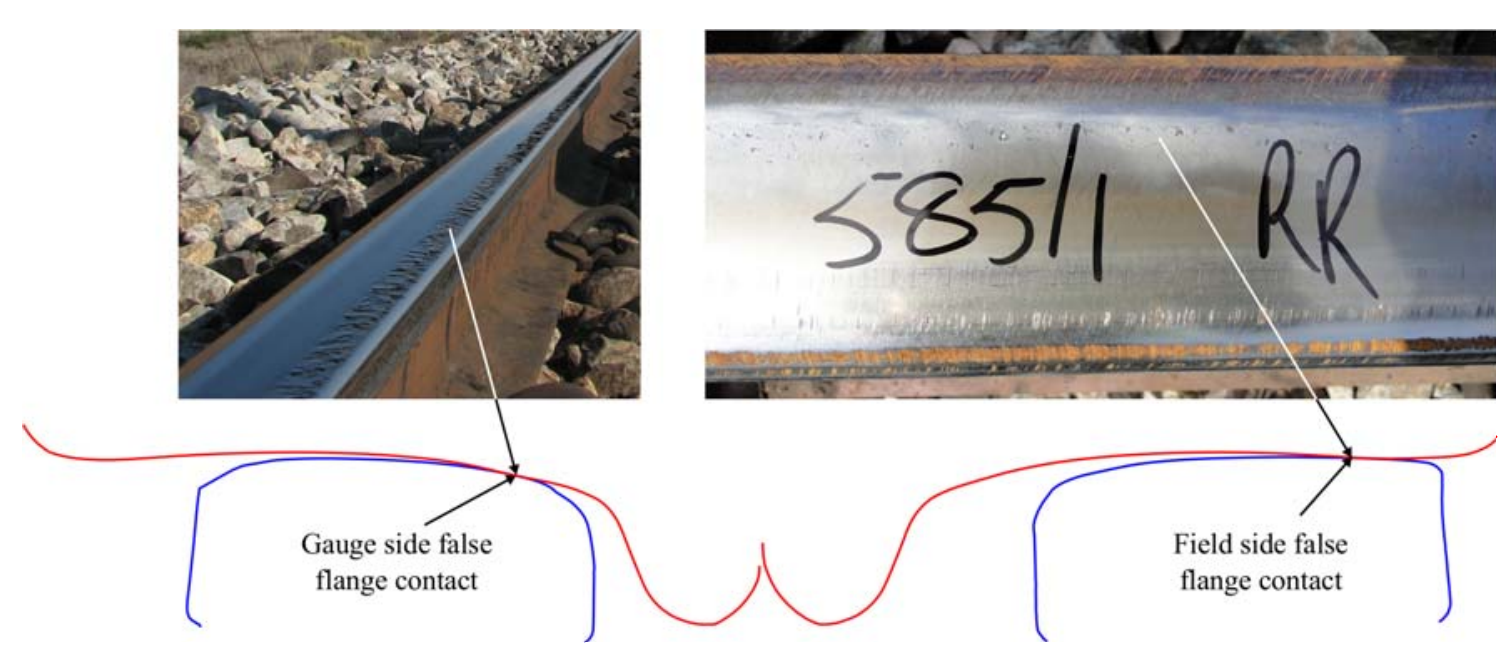

Figure 1: False flange contact with the high and low rail

The use of head-hardened rails to reduce rail wear is common on heavy haul railway lines and has exacerbated the effect of RCF damage on rails. Dikshit et al. [7] suggested that the higher wear resistance of head-hardened rails causes rails to retain their shape much longer prolonging adverse worn wheel contact with the as-ground rail profiles. This wear resistance results in an increase in surface-initiated RCF, because the adverse contact conditions are sustained and the RCF cracks are not naturally worn away.

Both wear and RCF drive the cost of wheel and rail replacement and maintenance. With the introduction of Scheffel's self-steering bogies on the iron ore line, rail maintenance had to shift its focus from the treatment of wear to a strategy where wear and RCF damage is balanced. Grinding of rails is used to maintain the rail shape and to control surface-initiated RCF cracks. Grinding can however be a costly exercise and excessive grinding will lead to reduced rail life [8]. Rail maintenance costs can thus be lowered by reducing the initiation of RCF which allows an increase in the rail grinding interval and ultimately reduce rail replacement costs. A strategy to reduce the occurrence and severity of surface-initiated RCF is therefore sought.

This study evaluates the effectiveness of 1 . Suspension changes that spread wheel wear across the tread and 2. Changes in rail profile designs. Multi-body dynamics simulations together with a wear prediction algorithm are used to investigate the effectiveness of the mitigation measures.

\section{FACTORS THAT INFLUENCE RAIL RCF DEVELOPMENT}

Wheel profile design is one of the main factors that influences the initiation and growth of surface-initiated RCF cracks. The wheel profile design used throughout this study was a Number 21 wheel profile which was developed in South Africa to suite the prevailing rail conditions. The development of this profile is described by Fröhling [9]. The wheel profile is shown and compared with a S1002 wheel profile in Figure 2.

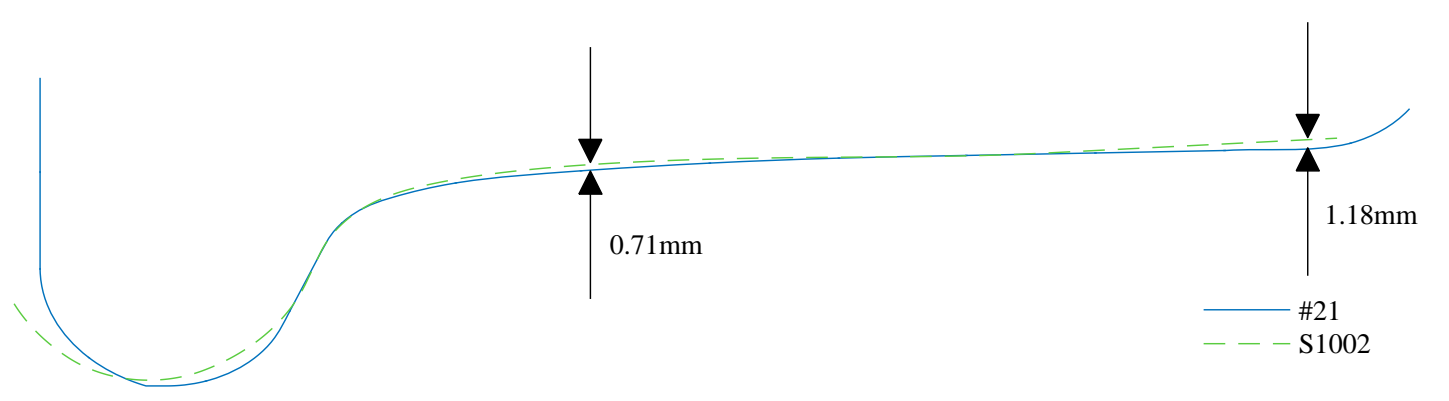

Figure 2: Comparison of the Number 21 and $\$ 1002$ wheel profiles 
Hollow wear on wheels and the subsequent development of false flanges, play a significant role in rail RCF initiation. The relationship between hollow wear and surface-initiated RCF on rails has been discussed by Tournay and Mulder [4]. A $2 \mathrm{~mm}$ hollow wear limit was proposed to reduce contact stresses as well as tangential steering forces. According to the shakedown diagram of Johnson [10] this will result in a reduction of RCF initiation. The relationship between hollow wear and RCF initiation was further investigated by a number of authors $[5,6,11]$ and [12]. These authors highlighted the relationship between hollow wear and surface-initiated RCF cracks. Tournay and Mulder [4] found that hollow worn wheels cause contact beyond the hollow wear band increasing the risk of RCF initiation. The severity of RCF damage can be linked to the hollow worn wheel shape $[6,11]$. It is therefore important to spread the wear across the wheel tread to maintain its original shape as far as possible and limit false flange formation.

Various bogie and wheel designs have been proposed to spread wear across the wheel tread. Scheffel [13] argued that hunting stability could be maintained for longer distances if the wheel profile is not changed much by wear. The original shape of the wheel could potentially be maintained longer by spreading the wear across the wheel tread through bogie and wheel design. Wheel designs capable of spreading wheel wear have been investigated by Shevtsov [14] and Polach [15]. In the current paper a change in the transverse stiffness of the primary suspension will be investigated as one of the ways of spreading the wheel wear across the tread and reducing RCF initiation.

Anti-head check wheel and/or rail profile designs could also be used to limit the initiation of RCF. The aim of anti-head check profiles is to eliminate contact at the locations where RCF cracks are generally observed by removing material at these locations. This approach was mentioned by Stow et al. [16] in the design of the P12 wheel profile and was applied to wheel profile designs by Shevtsov [14] and Shevtsov et al. [17]. Anti-head check wheel and rail profiles that are used in Sweden and the United Kingdom are discussed by Persson et al. [18], Evans and Iwnicki [8], Stow et al. [16] and Iwnicki [19]. Schöch [20] discussed the application of antihead check rail profiles in Europe. The anti-head check rail profiles have gauge corner relief up to $0.6 \mathrm{~mm}[8,20]$. Evans and Iwnicki [8] even suggested a larger rail inclination to get more gauge corner relief. Stow et al. [16] argue that an anti-head check wheel profile, such as the P12 wheel profile, could be applied in addition to anti-head check rail profiles to increase the gap between the wheel and the gauge corner of the rail. These studies showed that anti-head check profiles could reduce RCF initiation and growth. In the current paper two rail profiles with gauge corner relief will be investigated.

Other factors may also influence the development and growth of RCF cracks. It is widely accepted that fluid contaminants, including lubricants, entering the crack often accelerate crack growth $[21,22,23]$. Due to the incompressible nature of these contaminants, they will cause pressurisation once they become trapped as a wheel passes over the crack accelerating the crack growth rate.

Banitic steels provide an alternative to pearlitic steels and have a lower carbon content. A ductile material is produced through rapid cooling that is said to be more resistant to RCF and shelling, but due to the lower carbon content, it is expected to have higher wear rates than pearlitic steels [24]. The probability of initiating RCF cracks can be reduced by increasing the resistance of the material to yielding [21].

\section{Increasing the transverse primary suspension stiffness}

$\mathrm{RCF}$ initiation is a function of curve radius [8,25-28], because of the higher steering forces in sharper curves. Scheffel's self-steering bogie design provides a soft yaw constraint to the wheelset which allows the wheelsets to approach a pure rolling position in curved tracks. This flexible yaw constraint is provided by the primary suspension of the bogie. The self-steering bogie design has a superior curving ability with reduced flange forces and energy dissipated by slip or creep [2].

Spreading the wheel wear across the tread is one way in which RCF, initiated by hollow worn wheels, could be reduced. In principle the wheel wear can be spread across the tread by reducing the steering ability of the self-steering bogies. An on-track test was thus performed with load 


\section{U. Spangenberg et al.}

measuring wheelsets to evaluate the effect of increasing the primary suspension stiffness of the self-steering bogie. As no significant changes could be made in the transverse stiffness of the primary suspension the test was inconclusive.

Simulations with increasing suspension stiffness were performed to determine its influence on wear and RCF. The primary suspension stiffness was increased by a factor of one and a half, two and five, respectively. A stiffness increase by a factor of five approaches the stiffness of a conventional three-piece bogie design.

\section{Rail profile designs}

Three rail profiles designs were considered during the study. These profiles included the iron ore line target profile, Rail Profile A with slight gauge corner relief and Rail Profile B with more significant relief in the gauge corner. The gauge corner relief of Rail Profiles A and B were developed using two alternative approaches. The iron ore line target rail profile has a similar shape to the UIC60E1 rail profile inclined at 1:20. However, it has a higher field side than the UIC60E1 rail profile. The iron ore line target and Rail Profile A were constructed from tangentially connected arcs. The construction of the iron ore line target starts from a $50 \mathrm{~mm}$ radius on the field side, progressing to a $300 \mathrm{~mm}$ radius on the crown, then a $50 \mathrm{~mm}$ radius on the gauge corner and ends with a $13 \mathrm{~mm}$ radius.

The grinding tolerances required are similar to international standards requiring Class Q [29] reprofiling. The tolerance applied is $\pm 0.3 \mathrm{~mm}$. The manner in which grinding maintenance is performed together with the required grinding tolerance often results in a rail profile with a pronounced crown. These profiles usually comply with the grinding tolerance, but are close to the tolerance limit. Rail Profile A was constructed to approach the target profile's re-profiling limit. Rail Profile A started with a $55 \mathrm{~mm}$ radius at the field side progressing to a $200 \mathrm{~mm}$ radius on the crown, then a $60 \mathrm{~mm}$ on the gauge corner and ending with a $10.25 \mathrm{~mm}$ radius.

Rail Profile B was based on the UIC60E1 1:20 anti-head check SNCF profile described by Schöch [20]. Rail Profile B was generated from the iron ore line target profile by removing $0.6 \mathrm{~mm}$ from the profile at $-13.4^{\circ}$ on the gauge corner with a straight line. Rail Profile B thus does not have a smooth tangential transition in this portion of the profile. The profiles are compared in Figure 3. The profiles were aligned at $-2.86^{\circ}$ and $-45^{\circ}$.

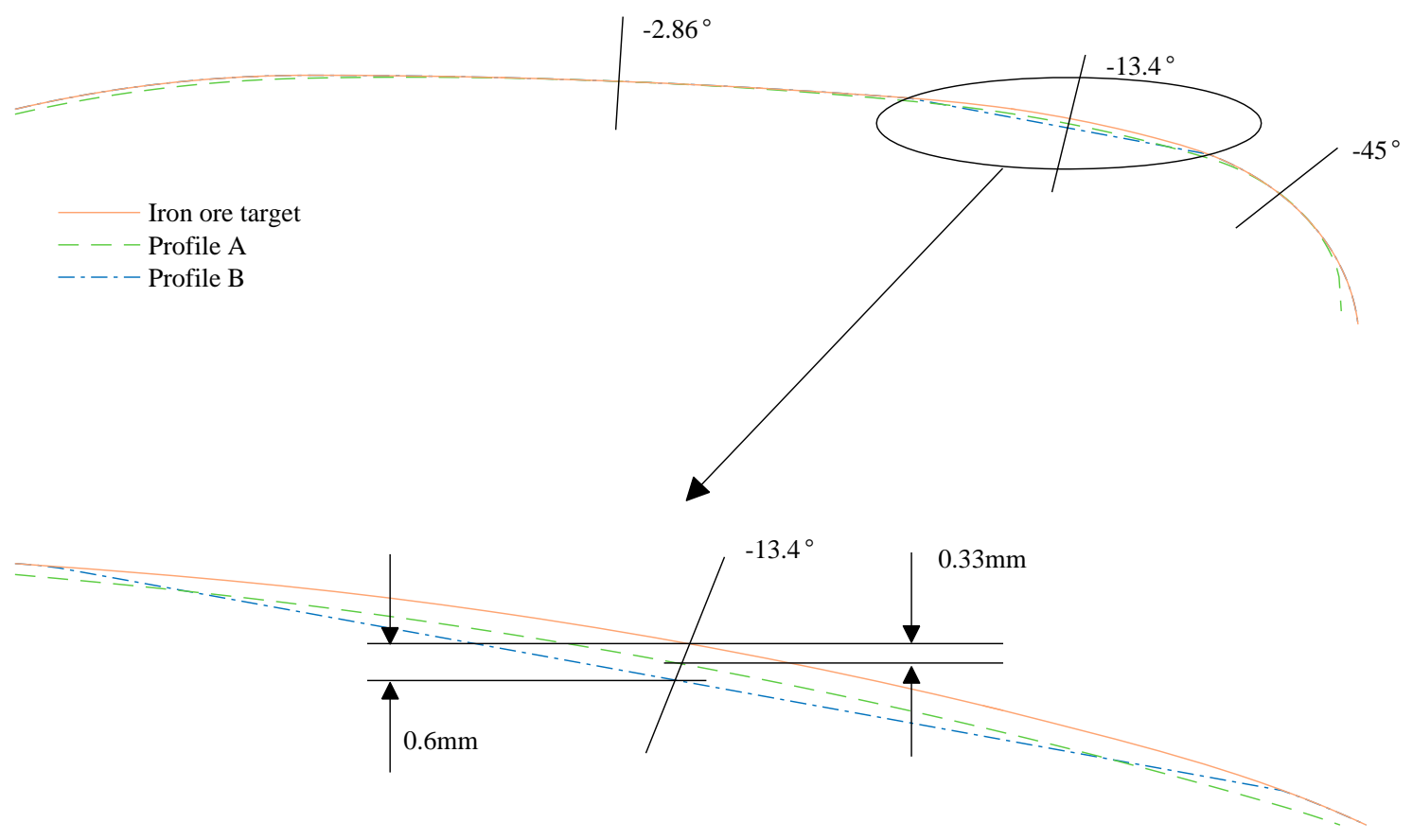

Figure 3: Iron ore line target compared to Rail Profile A and B 
Three different virtual tracks were created for the investigation. One track was created with the iron ore line target rail profile applied along the full length of the virtual track. This track was used to investigate the effect of increasing the transverse primary suspension stiffness. Another two tracks were created for the investigation of the rail profile designs. The first of these tracks had Rail Profile A applied along the full track length. The second track contained both the iron ore line target profile and Rail Profile B. Rail Profile B was only applied to the high leg in curves. The iron ore line target profile was used as the tangent and low leg rail profile.

\section{WHEEL-RAIL INTERFACE DAMAGE}

Kimura et al. [23] analysed the elemental processes that affects wear and RCF and noted that the elemental processes are similar. Essentially, if wear dominates, RCF is usually reduced and vice versa.

The long-term behaviour of profiles must thus be evaluated to ensure that a low wear rate and reduced risk of RCF initiation is maintained as suggested by Nia et al. [30]. It is thus essential to predict wear and RCF to understand the long-term behaviour.

\section{Modelling wear damage}

Wheel and rail wear prediction algorithms utilise an iterative procedure in which the contacting forces are used to calculate wear. The wear is scaled based on the original profile and an updating strategy. This is achieved by updating the profile after a predetermined distance has been travelled, a predetermined tonnage has passed or a predetermined wear depth has been reached. Braghin et al. [31] provide an overview of the calculation of worn wheel profiles by means of multibody dynamic simulations. Tunna et al. [24] and Enblom [32] reviewed wheel wear mechanisms and wear prediction models.

Enblom [32] mentioned that there are currently two predictive wear models being employed in the railway context. The first model assumes that material loss is proportional to frictional energy dissipated during contact. The second model is based on Archard's wear model where material loss is proportional to the product of normal force and sliding distance and inversely proportional to the material hardness. Tunna et al. [24] and Pombo et al. [34] compared energy dissipation wear models to the Archard wear model. Good agreement was found between the different models.

Many researchers use the proportionality between the amount of worn material and the frictional energy dissipation in contact in an attempt to evaluate and predict wear (see [34-39]). Archard's wear model is commonly used in the tribology community to model sliding wear and has become more prevalent in wear prediction studies (see [27, 30, 33, 34, 40-44]).

The algorithm used by the VI-Rail's wear toolkit [45] to predict wheel and rail wear is based on the proportionality between the worn material and the energy dissipated during contact. The wear algorithm is embedded in the FASTSIM contact algorithm. The wear depth $(\delta)$ is calculated from Equation (1) [45].

$$
\delta=\frac{k\left(T_{x} \gamma_{x}+T_{y} \gamma_{y}\right) L}{A \rho}
$$

where $k$ is the wear coefficient, $T_{x}$ and $T_{y}$ are the tangential creep forces in the longitudinal and lateral directions respectively, $\gamma_{x}$ and $\gamma_{y}$ are the creepages in the longitudinal and lateral directions respectively, $L$ is the load path length of a particle travelling in the contact patch, $A$ is the contact area and $\rho$ is the material density. This algorithm only distinguishes between mild and severe wear.

Zobory [37] and Pombo et al. [34] noted that the wear coefficients employed by the wear algorithms are often dependent on the material properties as well as a transition value to distinguish between mild and severe wear. Jendel [40] proposed the use of a wear map that defines the value of the wear coefficient as a function of the contact pressure and the slip velocity to 


\section{U. Spangenberg et al.}

make the wear coefficients more general. Unfortunately, extensive material testing is required to determine the wear coefficients for accurate wear predictions.

According to Chudzikiewicz et al. [38] the wear coefficient $(k)$ in Equation (1) is based on work performed by Linder. The wear coefficient is defined as $4.5 \times 10^{-7} \mathrm{~g} / \mathrm{Nm}$ for mild or $1.25 \times 10^{-6} \mathrm{~g} / \mathrm{Nm}$ for severe wear. The wear coefficients were originally tuned by Linder to fit polygonal wheel wear predictions. The wear coefficients are specific to the material, condition and the analysis methodology applied by Linder and is not generally applicable. The wear coefficients used by VI-Rail's [45] wear algorithm are constant within the identified wear regime. Zobory's [37] and Chudzikiewicz et al. [38] discussed the assumption of constant wear coefficient in the mild and severe wear regimes. As the intention of this research is not to improve on current wear algorithms, the standard algorithm as implemented by VI-Rail's [45] wear toolkit was used. A validation of the algorithm is presented in Section 0 where predicted wheel wear is compared with measurements.

The transition from the mild to the severe wear regime is made when Equation (2) exceeds $4 \times 10^{6} \mathrm{~W} / \mathrm{m}^{2}[45]$.

$$
P_{d}=\frac{\left(T_{x} \gamma_{x}+T_{y} \gamma_{y}\right) v_{o}}{A}
$$

where $P_{d}$ is the frictional power density and $v_{o}$ is the mean velocity at the wheel-rail interface.

In this paper, the wear toolkit within VI-Rail [45] together with the load collective definition allows the prediction of wheel wear for a CR-13 wagon. During wheel wear prediction dry contact conditions were assumed. Although there are some uncertainties regarding the wear coefficients, a relative comparison of wear can be made.

A baseline running distance was defined by the distance that the baseline wagon and track configuration (see Table 2) required to reach $2 \mathrm{~mm}$ hollow wear. Hollow wear on wheels in this study is defined as the vertical distance from the worn profile to the original wheel profile at $82.5 \mathrm{~mm}$ from the back of the wheel flange. The wear and RCF simulations of the two mitigation measures were repeated until this baseline running distance was reached. The running distances of the various simulation scenarios were normalised with respect to the baseline running distance.

\section{Modelling RCF damage}

RCF observed on the iron ore line is confined to the gauge corner of the high rail and field side of the low rail. RCF cracks may grow to such an extent that they may unite, branching across the railhead causing spalling of the rail surface or resulting in a complete fracture of the rail [10]. The severe RCF damage observed on the high rail of curves on the iron ore export line is thus of concern. Ekberg and Kabo [21] provided an overview of the various RCF mechanisms as well as prediction and modelling methods. A more recent review of RCF was made by Tunna et al. [24]. Grassie [46] presented a broad overview of wear and RCF and practical experiences with such rail damage.

The prediction of surface-initiated RCF cracks was performed by post-processing the dynamic simulation results. The surface fatigue index [47] was applied to predict the initiation of RCF. The surface fatigue index (FI Surf $)$ is based on the shakedown map derived under the assumption of full slip by Johnson [10]. The shakedown map consists of the normalised vertical load or load factor $(v)$ on the $y$-axis and the utilised traction coefficient $(\mu)$ on the $\mathrm{x}$-axis. The working point on the shakedown map is determined from the normalised vertical load and utilised traction coefficient shown in Equations (3) and (4) [47], respectively.

$$
v=\frac{3 N}{2 \pi a b k_{e}}
$$




$$
\mu=\frac{\sqrt{T_{x}^{2}+T_{y}^{2}}}{N}
$$

where $N$ is the normal load, $a$ and $b$ the semi-axes of the contacting ellipse and $k_{e}$ is the shear yield strength of the material. The normalised vertical load and utilised traction coefficient was calculated for each contact patch based on the contact algorithm results. The rail material properties used during RCF modelling was that of UIC60 CrMn rails (see Table 1 as proposed by Fröhling et al. [11]). The minimum of the shear yield strength of 553MPa was used in Equation (3). All creep forces, lateral and longitudinal, were considered to contribute to RCF initiation. The surface fatigue index was calculated as the shortest distance between the working point on the shakedown map and the shakedown limit. The true distance was calculated to avoid the limitation of the horizontal projection surface fatigue index, which becomes inaccurate at very high utilised traction values and low normalised vertical loads [47]. The initiation of RCF is predicted when the $\mathrm{FI}_{\text {Surf }}$ value exceeds zero. Relative comparisons of the $\mathrm{FI}_{\text {Surf }}$ values were made to judge the RCF performance of the mitigation measures.

Table 1: UIC60 CrMn rail strength parameters [11]

\begin{tabular}{lr}
\hline Rail strength parameter & Value \\
\cline { 2 - 2 } & $\mathrm{MPa}$ \\
\hline Tensile yield strength & 590 \\
Ultimate tensile strength & 1080 \\
Yield strength in shear & 553 to 621 \\
\hline
\end{tabular}

\section{METHODS}

The two RCF mitigation measures together with their subcases that are evaluated to reduce RCF initiation are summarised in Table 2. The study of the two RCF mitigation measures is performed through multi-body vehicle dynamics simulations. Wheel wear is predicted from these simulations to study the effects that each of these measures have on the worn profile shape, the wear rate and RCF initiation.

Table 2: Summary of the baseline and two RCF mitigation measures

\begin{tabular}{clll}
\hline RCF mitigation measure & Subcase & Rail profile & Wheel profile \\
\hline Baseline & Baseline & Iron ore target & $\# 21$ \\
\hline 1. Increase transverse & 1.1. Stiffness x1.5 & Iron ore target & $\# 21$ \\
primary suspension & 1.2. Stiffness x2 & Iron ore target & $\# 21$ \\
stiffness & 1.3. Stiffness x5 & Iron ore target & $\# 21$ \\
\hline 2. Change in rail profile & 2.1. Profile A & Rail profile A & $\# 21$ \\
design & 2.2. Profile B & Rail profile B & $\# 21$ \\
\hline
\end{tabular}

\section{Vehicle dynamics analyses}

A vehicle model of a CR-13 type iron ore wagon was used to predict both wear and RCF during the wear life of the wheel. The analysis process started with a dynamic analysis being performed during which the wheel profile wear was calculated and the profile updated. The first dynamic analysis constituted the wear simulation. The wheel profiles therefore regularly changed during this dynamic analysis and subsequently influenced the vehicle's dynamic behaviour and contacting forces. The wear simulation was followed by a second dynamic analysis that used the updated wheel profiles. The results from the second dynamic analysis were used to predict RCF initiation. This second dynamic analysis constituted the RCF. Once the wear and 
RCF simulations were completed, the analysis process would be repeated until the predetermined travelling distance was reached.

\section{Vehicle model}

The vehicle dynamics modelling and simulations were carried out in VI-Rail [45]. The vehicle model consisted of a CR-13 type iron ore wagon fitted with two MkV self-steering freight bogies $[2,3]$. The CR-13 type wagon is the main wagon type running on the iron ore export line. The bogie model included non-linear friction elements to model the side bearers, the friction wedges and the centre bowl interface. These elements are standard in the VI-Rail Freight Toolkit add-on. The accuracy and validity of this model was presented by Spangenberg et al. [6].

\section{Load collective design}

Fröhling [25] and Jendel [40] discussed the importance and definition of a representative load collective for wheel wear predictions. The load collective generally includes a representation of the track layout, traffic conditions, wheel-rail profiles, coefficient of friction, track irregularities as well as vehicle braking and traction. There are many simplifying assumptions that can be made during the load collective design to ensure faster solution times while maintaining accurate wear predictions. The assumptions made by Fröhling [25], Enblom and Berg [33], Jendel [40] and Jendel and Berg [41] were considered when the load collective was designed.

Track layout: A single virtual track was built and all the simulations were performed on this virtual track. The layout of the virtual track was a scaled representation of the iron ore line, accounting for all tangents and curves based on their fractional occurrence. The total virtual track length was $8696 \mathrm{~m}$ with a $40 \mathrm{~m}$ run-in and a $320 \mathrm{~m}$ run-out. The curves had a $60 \mathrm{~m}$ long transition curve. The virtual track layout is shown in Figure 4(a).

Super-elevation: The super-elevation (cant) was assumed constant within a curve as shown in Figure 4(b). The relevant super-elevation was selected from Transnet Freight Rail's rail maintenance manual [48].

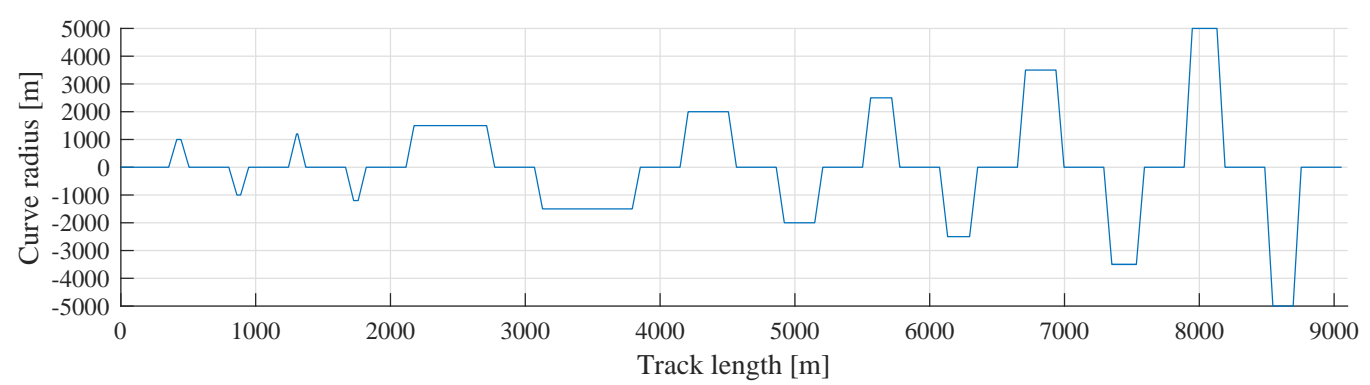

(a)

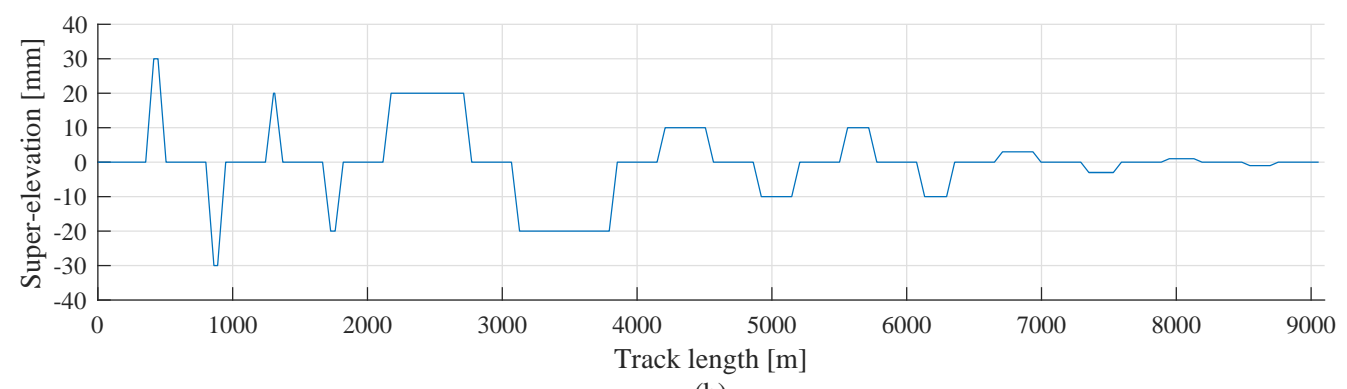

(b)

Figure 4: Representative (a) track layout and (b) super-elevation of the iron ore line 
Track Gauge: The track gauge on the iron ore line is $1065 \mathrm{~mm}$. The track gauge is widened by $5 \mathrm{~mm}$ in curves and for $30 \%$ of the tangent track it is widened by $10 \mathrm{~mm}$ to apply rail pummelling as described by Magel and Kalousek [49].

Traffic conditions: The wagons are periodically turned around and track symmetry can be assumed (cf. $[25,30])$. Based on the assumption of symmetry, the wear on the left and right wheels of the outer axles are expected to be similar. Similarly, the left and right wheels of the inner axles are expected to experience the same amount of wear. The wheel wear experienced by the four wheels on the outer axle and the four wheels on the inner axle was accumulated, producing two individual worn profiles. These worn profiles were used during the succeeding RCF and wear simulations.

The wear algorithm accumulates wear on the wheels as the vehicle runs over the track of Figure 4(a). Left and right hand curves were used in the track layout even though the assumption of symmetry was made. The track layout of Figure 4 was used to force the wheel to run on tangent track before and between curves of the same radius before progressing to the next set of curves. This was done to spread the contact points more evenly, since the wheel had to run on two tangent sections and proceed through four transition curves for a set of curves.

Wheel profiles: The original wheel profile used during simulations was the South African Number 21 wheel profile.

Rail profiles: Rail designs included the iron ore line target rail profile, Rail Profile A and Rail Profile B.

Coefficient of friction: A constant maximum coefficient of friction of 0.4 was allowed. Lubrication was not considered and dry contact conditions were assumed.

Track irregularities: Measured track irregularities of a single representative section of the track were used during all the simulations.

Vehicle speed and braking: A constant vehicle speed of $60 \mathrm{~km} / \mathrm{h}$ was used during the simulations. The effect of braking was not considered.

Contact algorithm: The FASTSIM contact algorithm was used during the dynamic simulations. The wear algorithm is embedded in this contact algorithm and calculates the wear depth during the wear simulation.

Wear data sampling: The wear algorithm sampled data every metre. VI-Rail's (2014) wear algorithm uses a wear scaling factor and the wear data sampling rate to calculate the worn amount. The circumferential wheel profile is updated once a given amount of wear has been accumulated. The track layout of Figure 4(a) together with the wear scaling factor, wear data sampling rate and wear coefficients allowed the baseline configuration (Table 2) to reach $2 \mathrm{~mm}$ hollow wear within 10 wear simulations. This provided the best balance between material removal per wear simulation, the number of wear simulations and the cumulative total simulation time required to reach $2 \mathrm{~mm}$ hollow wear.

\section{RESULTS OF WEAR AND RCF DAMAGE PREDICTION}

The two RCF mitigation measures were evaluated and compared to the baseline arrangement. The wear rates and potential to initiate RCF were examined to evaluate the success of the RCF mitigation measures while maintaining a low wheel wear rate. The wear results shown in the discussions on wear are associated with the wear of the outer axles. The results for the inner axles are not shown, but illustrated similar wear behaviour.

\section{Wear algorithm verification}

The wear algorithm of VI-Rail [45] was verified by comparing the predicted worn profile of the baseline simulation at approximately $2 \mathrm{~mm}$ hollow wear with measured wheel profiles (Figure 5(a)). The running distances of the wheels were not compared, since the wear coefficients were not tuned for the wheel and rail materials and simulation conditions. The worn profile wear is compared quantitatively in Figure 5(b) and shows that the simulated and measured profiles are similar between -25 and $10 \mathrm{~mm}$. The biggest differences in profiles occurs at the gauge side and field side false flanges, respectively at -38 and $20 \mathrm{~mm}$. The difference at the gauge side and field side false flanges can partly be attributed to the use of a single representa- 


\section{U. Spangenberg et al.}

tive track irregularity spectrum. When more than one spectrum of irregularities is used, the wheel tread wear may be spread more widely, since the variation in additional irregularity spectra may force the wheel to displace more laterally. The false flange difference may in addition be explained by the exclusion of worn rail profiles during the wear simulations. The exclusion of switches and crossings in the load collective has been discussed by Nia et al. [30]. This exclusion, could partially account for the limited field side wear and large differences between the simulated and measured profiles at the field side false flange.

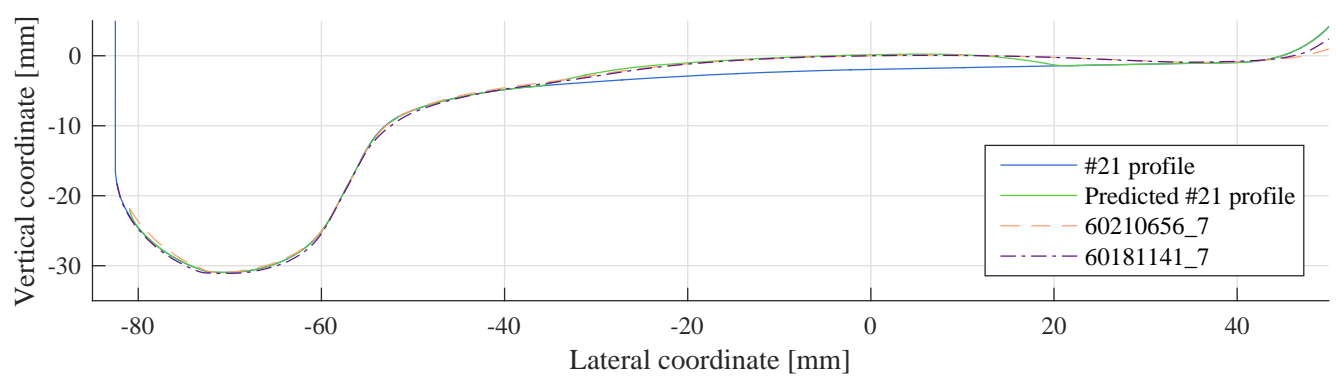

(a)

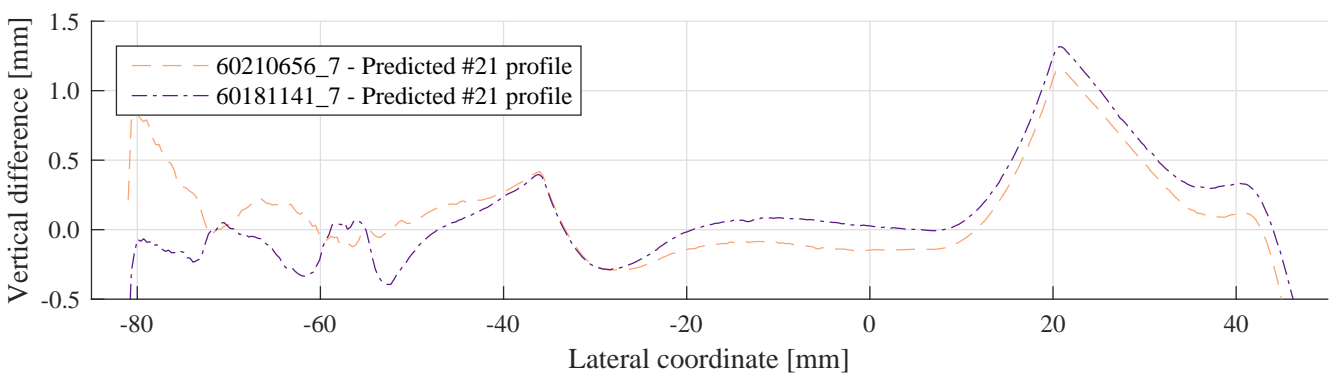

(b)

Figure 5: Comparison of wheel wear of a Number 21 wheel profile and measurements (a) profiles and (b) vertical differences

A second verification was performed with a similar load collective design as described for the iron ore export line, but the track layout was changed to that of the South African coal export line. The predicted worn profile with approximately $1.5 \mathrm{~mm}$ hollow wear is compared to a measured wheel profile with $2 \mathrm{~mm}$ hollow worn wheels in Figure 6(a). The worn wheel profiles in Figure 6(b) shows a constant difference of $0.5 \mathrm{~mm}$. Similar differences are noticeable at the gauge and field side false flanges, respectively at -44 and $25 \mathrm{~mm}$. The difference at the false flanges can be attributed to the use of a single track irregularity spectrum, exclusion of worn rail profiles as well as switches and crossings. The similarities in wear amounts across the hollow wear band in both cases show that the wear algorithm performs reasonably well. 


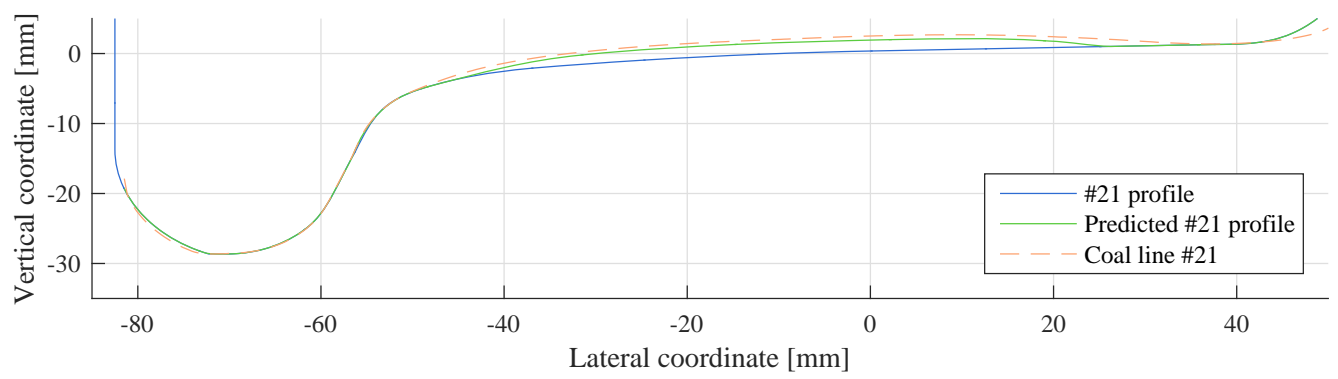

(a)

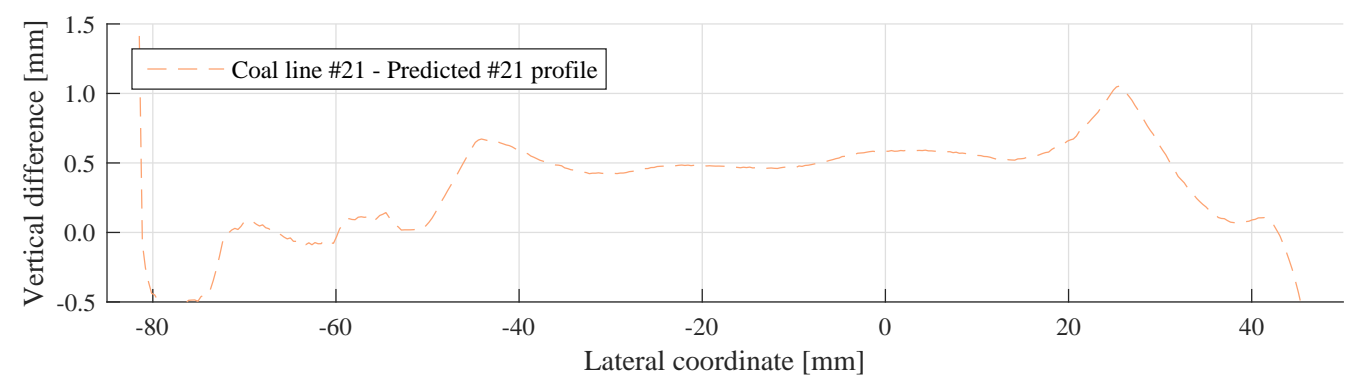

(b)

Figure 6: Comparison of wheel wear of a Number 21 wheel profile and coal line measurement (a) profiles and (b) vertical differences

\section{Wear as a result of suspension stiffness changes}

The influence that an increase in the transverse stiffness of the primary suspension has on the wheel wear was investigated by increasing the stiffness by a factor of one and a half, two and five. The predicted worn wheel profiles close to $2 \mathrm{~mm}$ hollow wear for these suspension changes are compared in Figure 7(a). The normalised distance to reach approximately $2 \mathrm{~mm}$ hollow wear was $80 \%, 70 \%$ and $40 \%$ respectively for the increase in suspension stiffness.

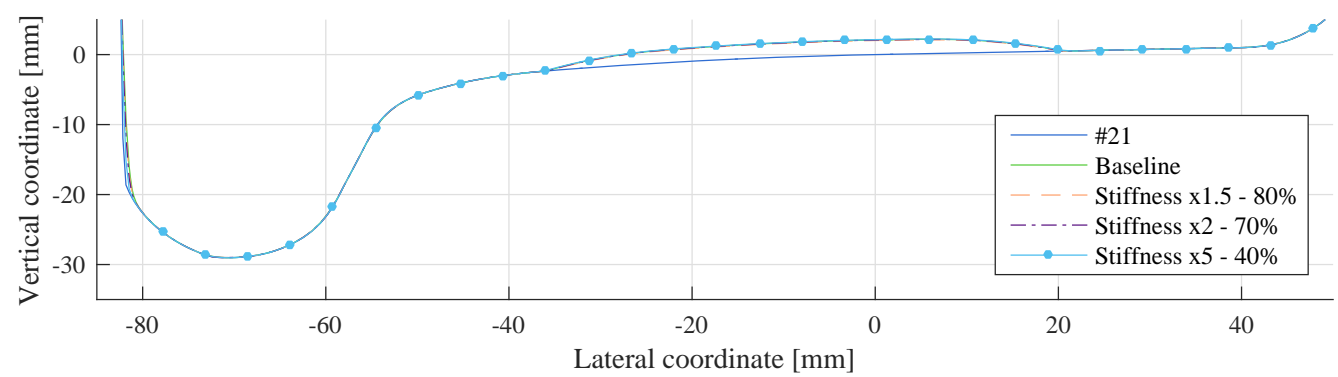

(a)

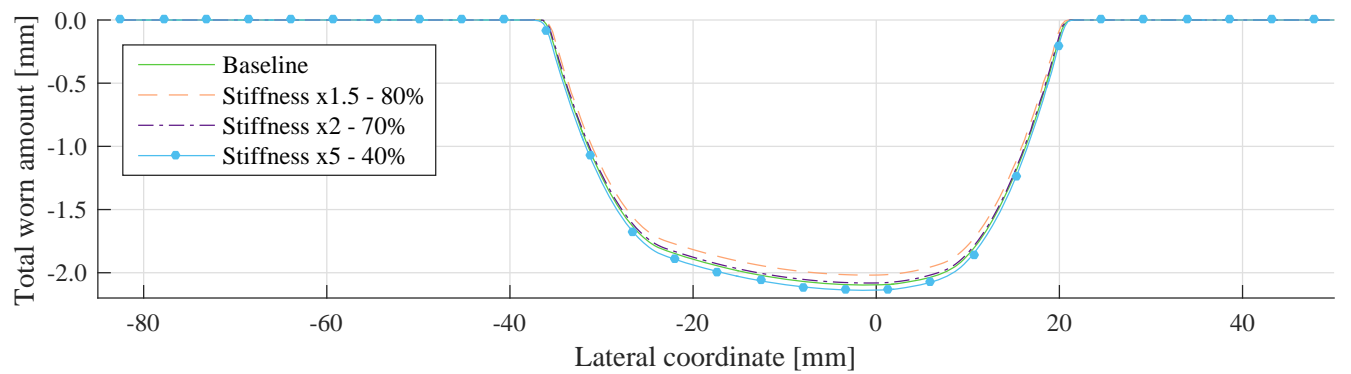

(b)

Figure 7: Wheel wear predictions at $\sim 2 \mathrm{~mm}$ hollow wear as a function of suspension stiffness, (a) profiles and (b) total worn amount 


\section{U. Spangenberg et al.}

The total wear predicted due to the three stiffness increases is similar to the baseline in the centre of the wheel tread (Figure 7(b)). There is only a slight increase in the spread of hollow wear when the primary suspension stiffness is increased. Even if the primary suspension stiffness is increased to five times the baseline stiffness the wear is only spread between -38.7 and $21.6 \mathrm{~mm}$ compared with -37 and $22 \mathrm{~mm}$ for the baseline arrangement. This increase in the spread of the hollow wear is very small and can be neglected. With worse steering it appears that the wheelset is still able to generate high enough steering forces to curve without contacting more towards the flange side or field side of the wheel profile. This could partially be explained by the fact that the ore line is relatively straight with $75 \%$ of the track being tangent or having curve radii larger than $3000 \mathrm{~m}$. The minimum curve radius on this line is $1000 \mathrm{~m}$. The wheel wear at the centre of the tread is dominated by the wear accumulated on tangent track and large radius curves and thus the wheel wear is not spread across the tread. This result is specific to the track layout, bogie type and wheel and rail profiles used on the iron ore line. It is expected that the hollow wear band would remain the same if this result is extrapolated to a bogie with softer primary suspension. All the worn profiles show false flange formation and according to the findings of Fröhling et al. [11] and Spangenberg et al. [6] this worn shape of the wheel is undesirable since it is more conducive to RCF initiation.

The disadvantage of increasing the primary suspension stiffness is evident from Figure 8(a). As the primary suspension stiffness is increased, the area that is worn off becomes larger. The increase in primary suspension stiffness results in an increase in steering forces which causes an increase in the wear rate. The increase in the area that has been worn off is partly due to the increased steering forces, but also due to the wheel wear being spread across the wheel tread. The wheel cannot contact the rail in the hollow-worn section as the hollow wear becomes progressively deeper. The wheel has to contact more towards the edges of the hollow-worn section which results in the wheel wear being spread across the wheel tread. The area worn off increased with increasing primary suspension stiffness and resulted in an increase in the hollow wear rate. The increase in hollow wear rate is reflected in the comparison of hollow wear depth (Figure 8(b)). The distance travelled to reach the $2 \mathrm{~mm}$ hollow wear limit is progressively reduced. The distances travelled to reach this limit are equal to $79 \%, 67 \%$ and $37 \%$ of the baseline distance for the suspension stiffness increase by a factor of one and a half, two and five respectively. Therefore, any change in primary suspension stiffness will cause a negligible spread in wheel wear for wheels with $\sim 2 \mathrm{~mm}$ hollow wear, but will increase the hollow wear rate. The wear life of the wheel profiles is thus reduced by increasing the primary suspension stiffness. This in turn will result in increased wheelset re-profiling and replacement costs. This increase in hollow wear rate is thus unwanted. The low wear rate achieved by the baseline suspension stiffness supports the use of Scheffel's original self-steering design rather than a conventional threepiece bogie design. An increase in wheel life could potentially be achieved if the suspension stiffness is decreased. 


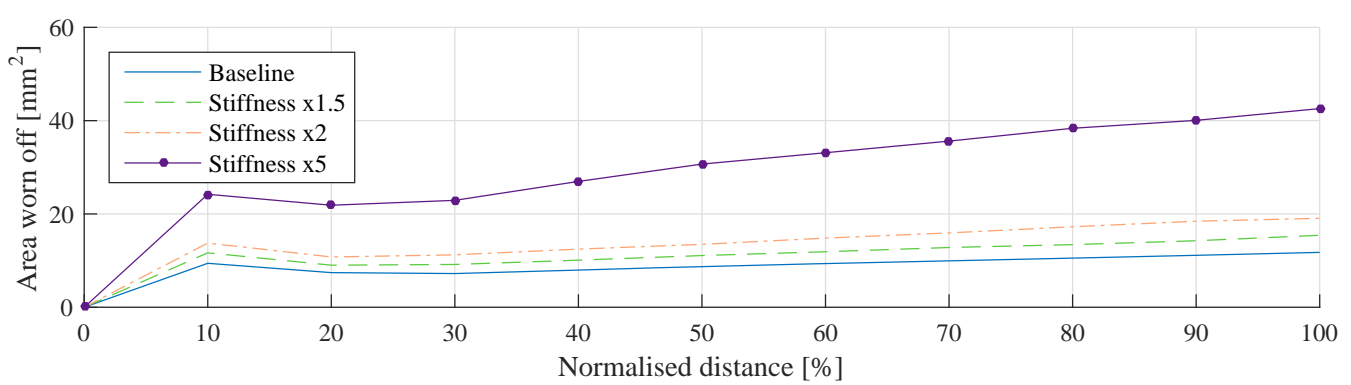

(a)

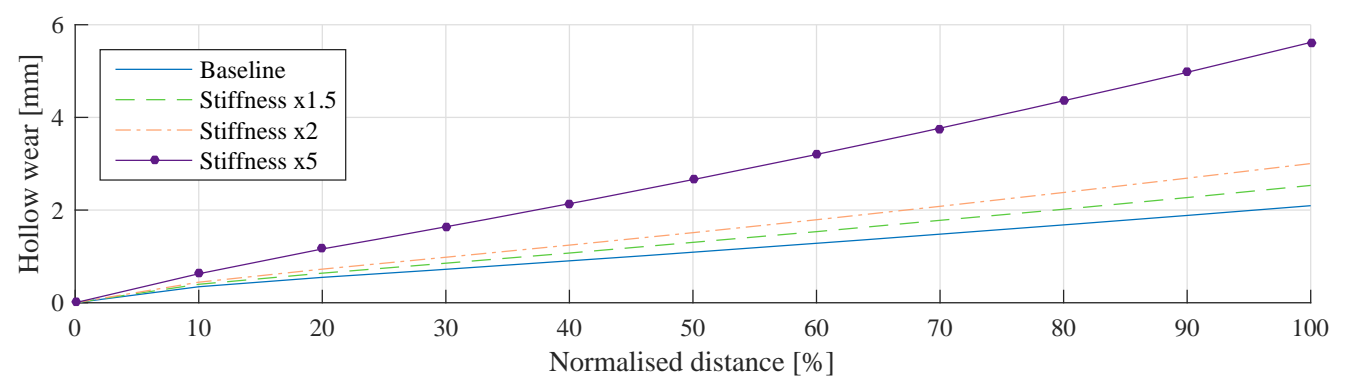

(b)

Figure 8: Suspension stiffness induced wear progression with (a) area worn off and (b) hollow wear

\section{Wheel wear caused by the rail profile designs}

The influences of rail profile changes on the worn wheel profile shapes were analysed using the iron ore line target rail profile, Rail Profile A and Rail Profile B. The worn wheel profiles that were predicted for these rail profile changes are shown in Figure 9(a). Note that the worn wheel profiles caused by Rail Profiles A and B are shown after $90 \%$ and $80 \%$ of the baseline distance, respectively.

The hollow worn shapes of the wheel profile produced by the baseline and Rail Profile A differ more significantly at the centre of the wheel tread than the wheel profile worn by Rail Profile B (Figure 9(b)). The hollow wear is more pronounced with Rail Profile A.

The worn wheel profiles produced by the baseline and Rail Profile B are similar at the centre of the tread. This can be attributed to the fact that the tangent rail profile remained the same for the baseline simulations and the simulations including Rail Profile B. The only difference was at the high leg of the curves and even then the gross part of the profiles was similar with only the gauge corner being lowered. There exist variations in the shape of the wheel worn by the target rail profile and Rail Profile B at the false flanges located at -36 and $20 \mathrm{~mm}$. The prominence of the false flanges of the wheel profile worn by Rail Profile B is reduced. The wheel profile must therefore have been able to contact Rail Profile B at these false flanges to wear it away. In addition to the false flange differences, the wheel profile worn by the Rail Profile B has a widened hollow wear band. This illustrates the influence of relief on the gauge corner of the rail profile. The wheels are forced to displace more laterally to attain the required rolling radius difference. The larger lateral displacements cause a spread in wear on the wheel tread and simultaneously the wheel is able to contact the rail at the false flanges in order to wear it down. This contact at the false flange effectively smoothens out the shape of the false flanges. 


\section{U. Spangenberg et al.}

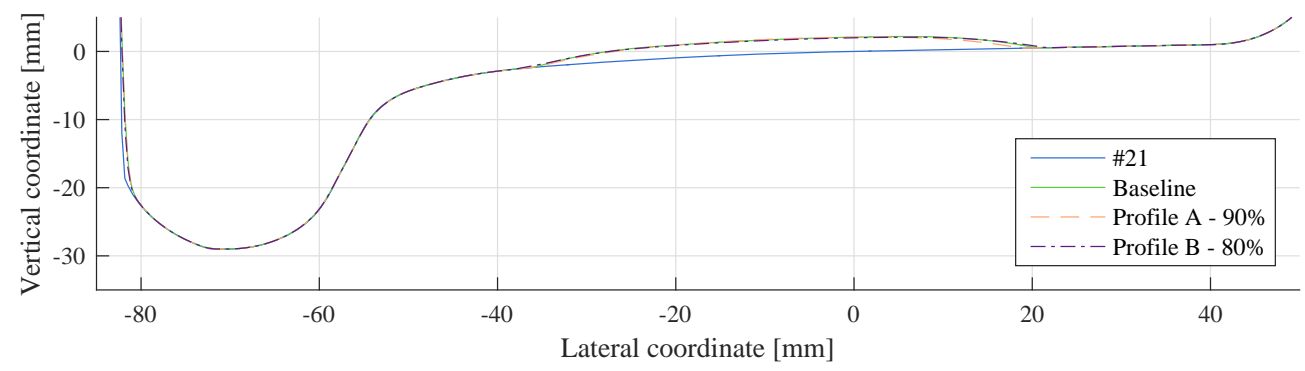

(a)

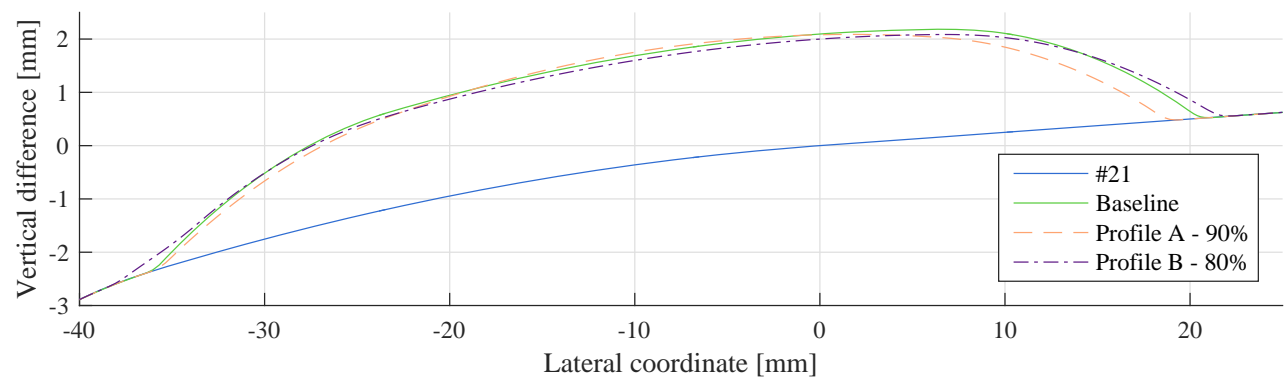

(b)

Figure 9: Wheel wear predictions at $\sim 2 \mathrm{~mm}$ hollow wear as a function of rail profiles changes, (a) profiles and (b) zoomed hollow wear band

The wear performances of the wheels caused by the different rail profiles are shown in Figure 10. The wheel wear rates produced by the Rail Profile A and Rail Profile B are on average higher than the baseline. This will have an influence on the hollow wear rate as shown in Figure 10(b). Rail Profiles A and B reach the hollow wear limit at $86.8 \%$ and $80 \%$ of the baseline distance respectively. The worn wheel profile caused by Rail Profile B could not reach the full baseline distance, because the worn off area became too severe (Figure 10(a)).

Rail Profile A was constructed with a crown radius equal to $200 \mathrm{~mm}$. The contact areas occurring on the crown will be smaller compared with the iron ore line target rail profile. The reduced contact areas will cause the wheel wear to occur in a narrower hollow wear band causing an increase in the wear rate.

Rail Profile B has a sharp transition from the iron ore line target rail profile with a relief of $0.6 \mathrm{~mm}$ on the gauge corner. There is no material available to contact and thus available for steering at the gauge corner of the rail profile. The wheelset is required to displace more laterally to attain the required rolling radius resulting in an increase in the steering forces. The increased steering forces will cause an increase in the wear rate of the wheels.

If either of these rail profiles is used, the wear life of the wheel profiles will be reduced, increasing the wheelset re-profiling and replacement costs. 


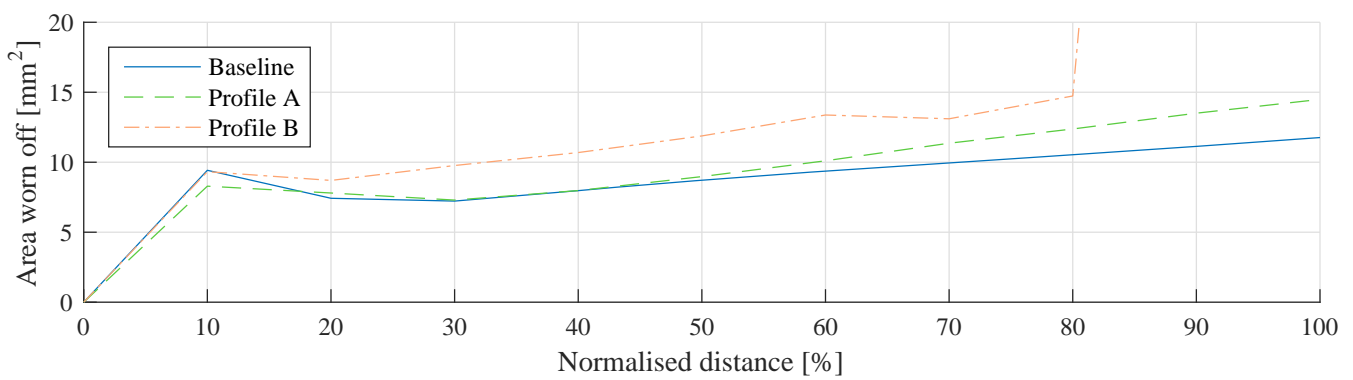

(a)

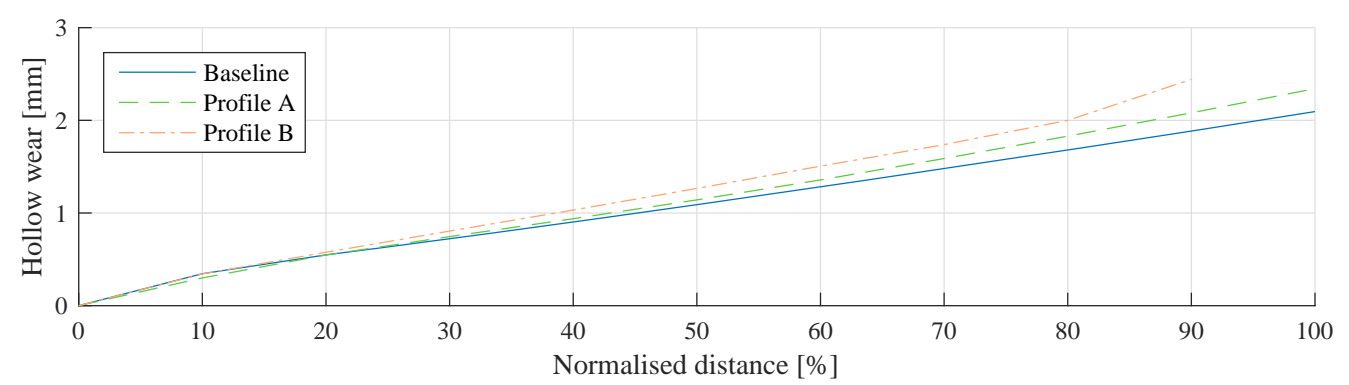

(b)

Figure 10: Rail profile induced wear progression with (a) area worn off and (b) hollow wear

The wheel profile wear caused by the Rail Profile B increased beyond $80 \%$ of the baseline distance (see Figure 10(a)). The wheel profiles at 80 and $90 \%$ of the baseline distance that were caused by Rail Profile B are compared in Figure 11. From Figure 11 it can be seen that the false flanges have been worn off, indicating that the wheel ran on the false flanges during the wear simulation. When running on the false flanges the normal contact pressure will increase and higher longitudinal creep forces are generated due to a larger rolling radius differential. A higher normal contact pressure will result in a higher normalised vertical load on the y-axis of the shakedown diagram. The higher longitudinal force may result in an increased utilised traction value on the $\mathrm{x}$-axis of the shakedown diagram if this force still satisfies Coulomb's friction law. If the increase in longitudinal force does not satisfy Coulomb's friction law, it will be bound to the maximum allowable coefficient of friction of 0.4. According to the shakedown map, an increase in the normalised vertical load and an increase in the utilised traction value will result in a higher probability of rail RCF, since the working point moves closer to the shakedown limit.

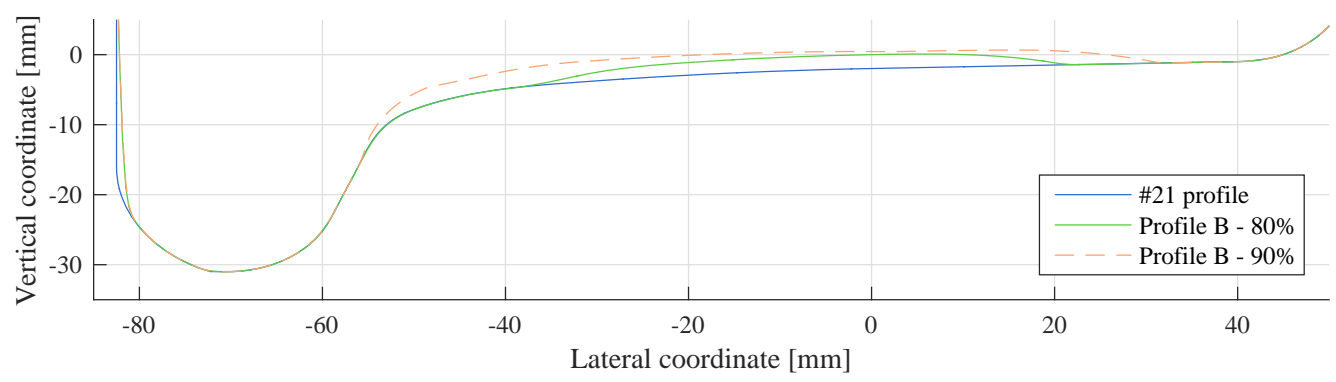

Figure 11: Wheel wear predictions of rail profile $B$ at 80 and $90 \%$ of the baseline distance

Pearce and Sherratt [36] showed the importance of wheel wear calculations to understand the evolution of the equivalent conicity. The increase in tread wear can be explained when evaluating the rolling radius difference and equivalent conicity of the worn wheel profiles that are produced by Rail Profile B at various stages of wear (see Figure 12). The rolling radius difference and the equivalent conicities of the worn wheel profiles produced by Rail Profile B were calculated with the ore line target as the low rail profile and Rail Profile B as the high rail profile. A positive lateral displacement indicates that the wheel flange moved closer to the gauge corner of 


\section{U. Spangenberg et al.}

the high rail. A discontinuity in the rolling radius difference graph becomes more severe with an increase in wheel wear (Figure 12(a)). The equivalent conicity graph of Figure 12(b) shows that the wheelset is unstable at a lateral amplitude of $0 \mathrm{~mm}$, becoming more stable at $3 \mathrm{~mm}$. The discontinuity in the rolling radius difference causes an increase in the equivalent conicity between 3 and $5 \mathrm{~mm}$.

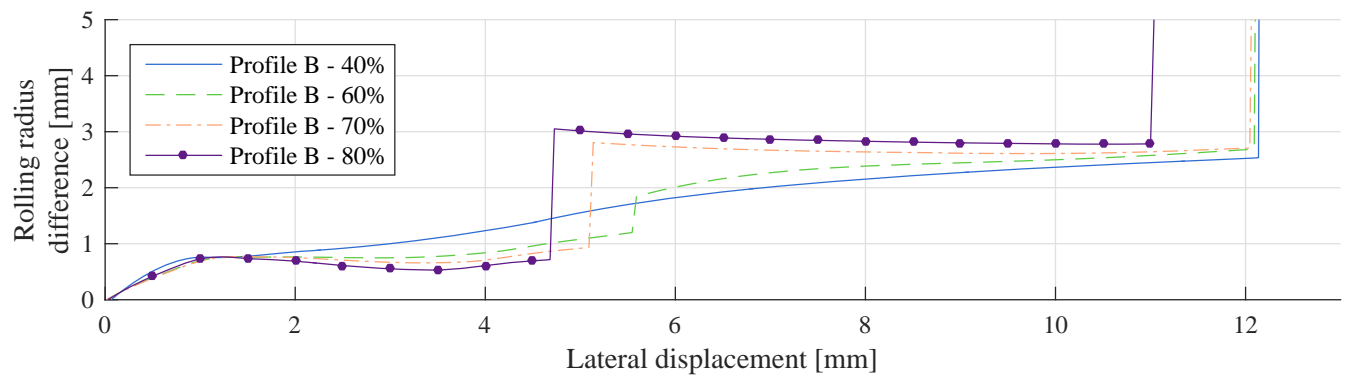

(a)

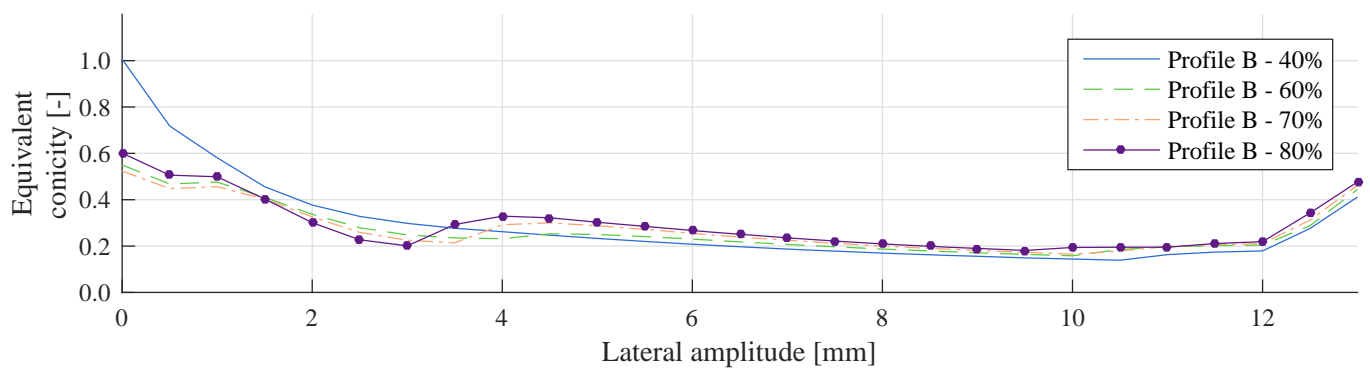

(b)

Figure 12: Comparison of the rail profile B wheel profiles' (a) rolling radius differences and (b) equivalent conicities

The simulations have shown that the $\mathrm{MkV}$ self-steering freight bogies require a rolling radius difference of approximately $1.1 \mathrm{~mm}$ to steer around a $1000 \mathrm{~m}$ radius curve. The profile at $80 \%$ of the baseline distance did not allow the wheel and rail profiles to achieve this rolling radius in a $1000 \mathrm{~m}$ radius curve before the discontinuity. The wheel will thus attempt to reach this required rolling radius by displacing laterally beyond the discontinuity. However, due to the sharp increase in the rolling radius and equivalent conicity, it will steer away from this discontinuity, reducing its lateral displacement. It will keep oscillating on this rolling radius discontinuity to traverse the $1000 \mathrm{~m}$ radius curve. Due to the large longitudinal and lateral steering forces generated during these oscillations the wheel wear will increase, wearing the false flanges. This will result in a sharp increase in the wear rate. This type of oscillation together with large steering forces and contact at the false flanges are observed in-field as oscillating RCF cracks on the high rail as shown in Figure 13. 


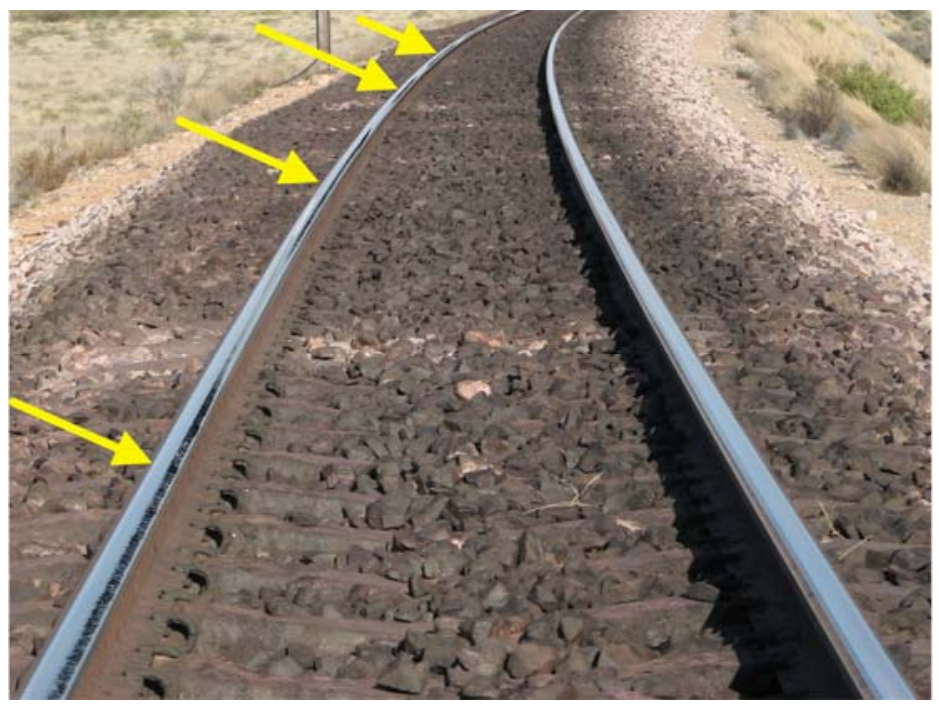

Figure 13: Oscillation of RCF observed in-field

The false flange wheel wear will cause a decrease in the equivalent conicity. The decrease in the wheel's equivalent conicity, together with the equivalent conicity decrease enforced by the lowered gauge corner of Rail Profile B [16], causes the wheel to contact over a wider area. This is evident from the initiation of flange wear of the wheel profile at $90 \%$ of the baseline distance (Figure 11). In-service rail profiles do not show such severe gauge corner relief as that of Rail Profile B. However, a severe increase in wheel wear after a certain distance could be a disadvantage of using a rail profiles with severe gauge corner relief such as Rail Profile B on the high rails of curves.

\section{Evaluation of RCF mitigation measures with worn wheels}

The long-term RCF performance of the two RCF mitigation measures needs to be evaluated to ensure that the probability of RCF initiation is reduced. The potential to initiate RCF on the rail surface is evaluated from the dynamic simulations of the worn wheels at different stages of wear. The RCF prediction only includes dynamic simulation results for wheel profiles up to approximately $2 \mathrm{~mm}$ hollow wear. The RCF prediction thus included dynamic simulation results up to $70 \%, 40 \%, 90 \%$ and $80 \%$ of the baseline distance for the wheel profiles worn as a results of the primary suspension stiffness increase by a factor of two and five as well as Rail Profiles A and B. The probability of initiating RCF was only evaluated on the high rail in curves. Since the left and the right wheel on the same axle experienced the same amount of wear, the $\mathrm{RCF}$ data is reported per axle. The long-term RCF performance is evaluated from the cumula-

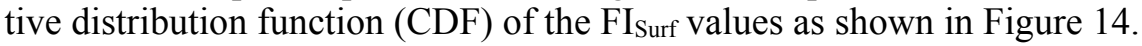

The baseline arrangement shows the lowest $\mathrm{FI}_{\text {Surf }}$ values over its running distance. The RCF prediction results for a stiffness change by a factor of two and five performed progressively worse compared with the baseline arrangement. This is due to larger steering forces. Higher steering forces results in larger utilised traction values in the curves and thus move the working points closer to the shakedown limit.

The contact conditions produced by the wheel profiles worn by the Rail Profile A are often similar to the contact condition produced by the worn wheel profiles caused by a factor five increase in suspension stiffness. This can be attributed to the rail profile being more pronounced, which reduces the size of the contact patches relative to those of the ore line target rail profile. Not only does the FI Surf values of Rail Profile A indicate a worse RCF performance, but also according to the findings of Fröhling et al. [11] and Spangenberg et al. [6], the worn shape of the wheel profile caused by Rail Profile A (Figure 9) is less suitable to reduce RCF initiation on worn rail profiles due to the pronounced false flanges of the wheel profile.

The worn wheel profiles produced by Rail Profile B have the worst RCF performance up to $50 \%$ of the CDF on all the axles. This is attributed to the fact that the wheel profile does not 


\section{U. Spangenberg et al.}

wear as conformal to the rail profile compared with the baseline case. The wheel profile is forced to wear the false flange away reducing the conformity of the wheel and rail profile. This results in reduced contact areas leading to larger $\mathrm{FI}_{\text {Surf }}$ values. The wheel contact points also move closer to the gauge side false flanges and the rail contact points move closer to the transition of the relief section of the rail profile. This causes a reduction in contact areas and increased steering forces leading to larger $\mathrm{FI}_{\text {Surf }}$ values.

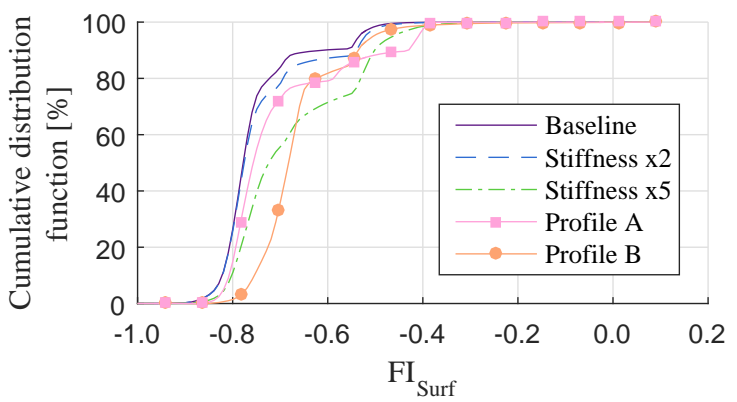

(a)

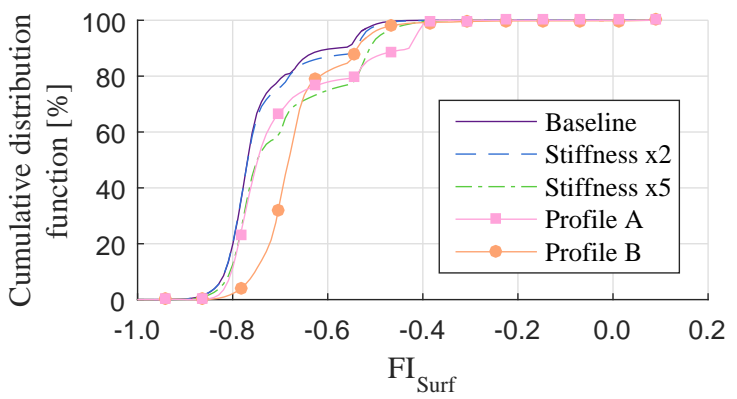

(c)

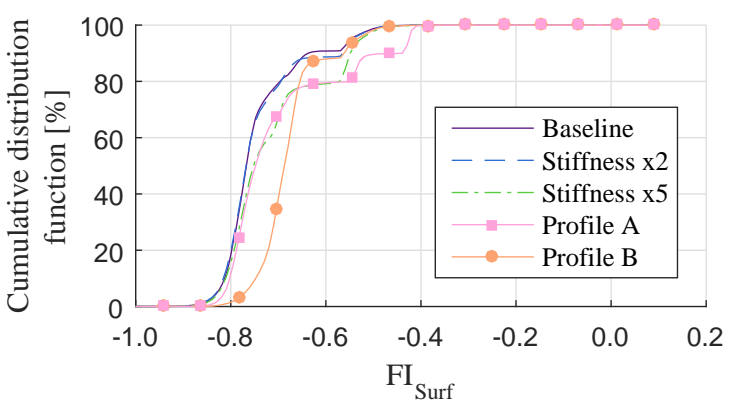

(b)

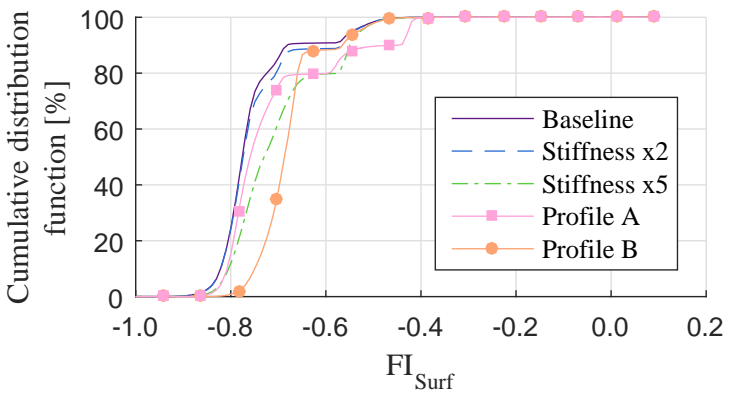

(d)

Figure 14: FIsurf cumulative distribution functions of RCF mitigation measures for wheel profiles up to $\sim 2 \mathrm{~mm}$ hollow wear on (a) axle one, (b) axle two, (c) axle three and (d) axle four

By zooming into Figure 14 it can be seen that the wheel profile produced by the Rail Profile $B$ exceeded the threshold at axles one and three (Figure 15). There are some instances where the gauge side false flange of the worn wheel contacted the relief section of Rail Profile B (Figure 16). Small contact areas are caused during this contact and if they are accompanied by large tangential creep forces the probability of initiating RCF is increased. Figure 16 illustrates con-

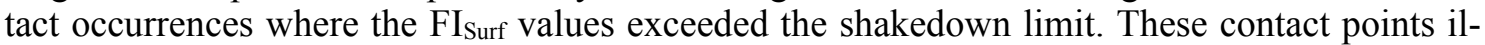
lustrate that the worn wheel profiles is able to contact Rail Profile B at the relief portion of the profile and could potentially initiate RCF. This confirms the finding of Stow et al. [16] that RCF damage returned to sites with gauge corner relief after a moderate tonnage.

This shows that the wheel profile produced by rail profile B could potentially initiate rail RCF. This analysis shows that the RCF performance of the wheel profiles produced by the baseline is desired. 


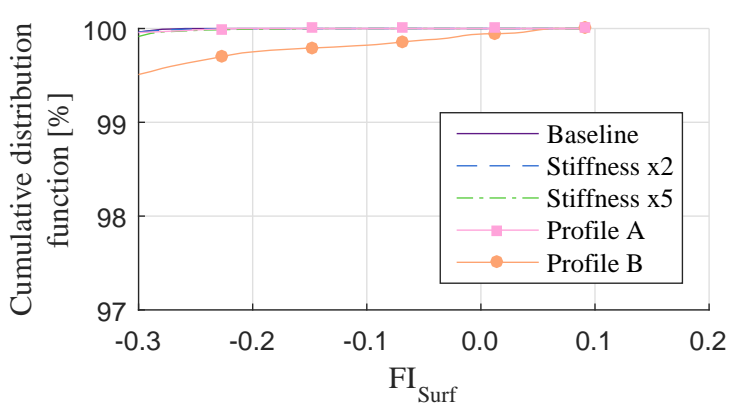

(a)

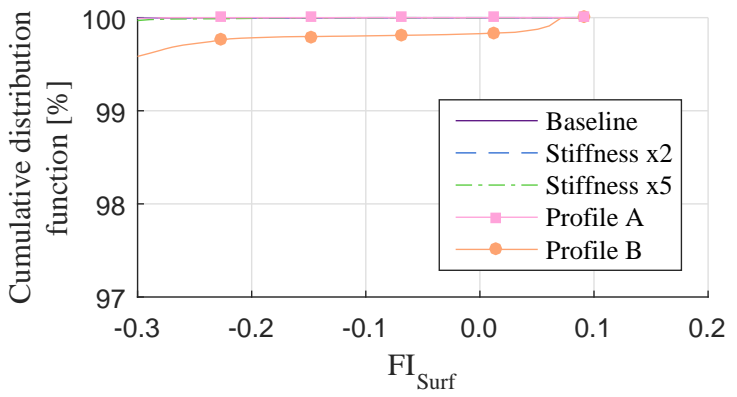

(c)

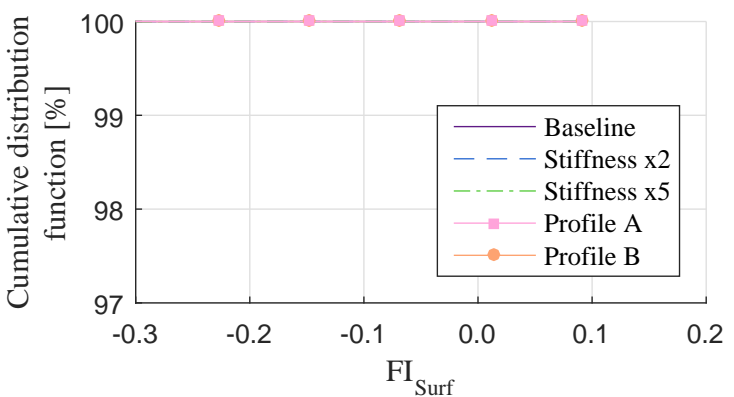

(b)

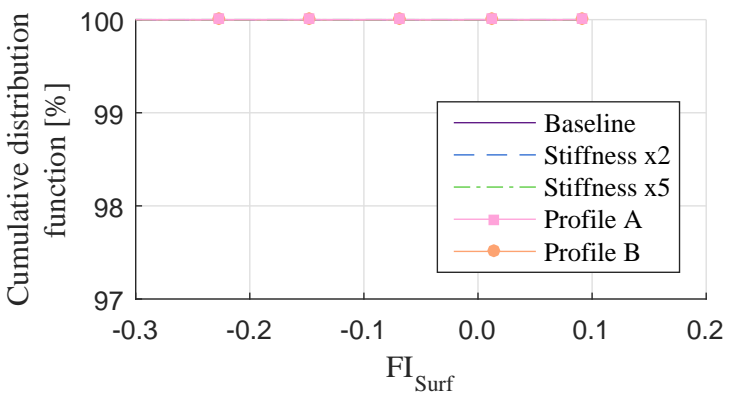

(d)

Figure 15: Zoomed FIsurf cumulative distribution functions of RCF mitigation measures for wheel profiles up to $2 \mathrm{~mm}$ hollow wear on (a) axle one, (b) axle two, (c) axle three and (d) axle four

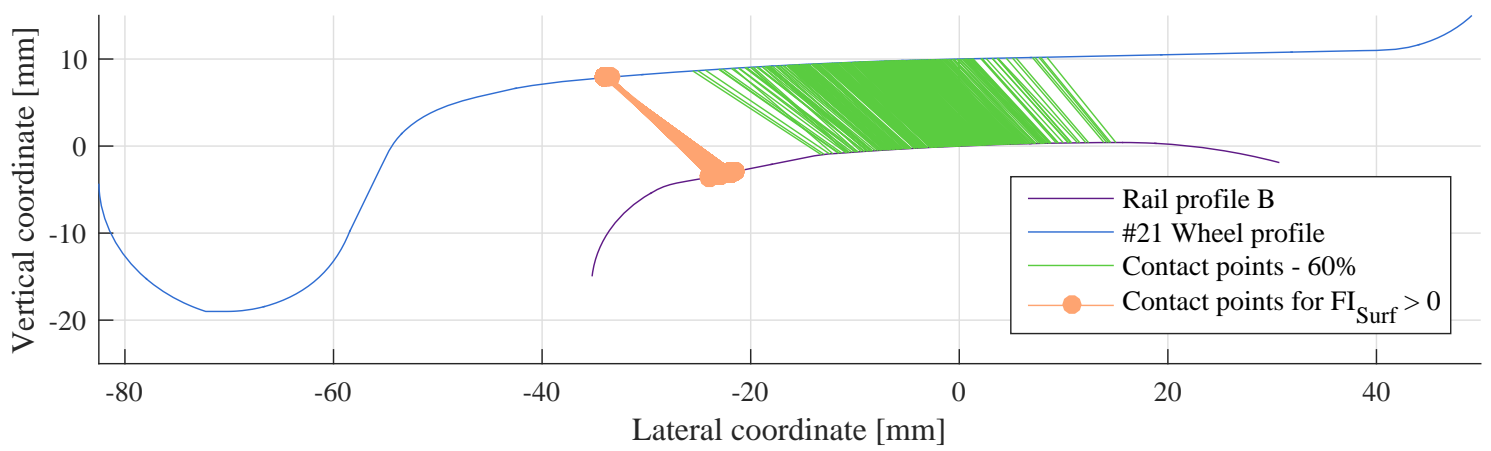

Figure 16: Representative contact points for rail profile $B$ and wheel profile at $60 \%$ of the baseline distance illustrating those contact points that exceed the shakedown limit

\section{CONCLUSION}

The wear and RCF performances of wheel profiles produced when applying two potential RCF mitigation measures have been studied. The worn wheel profiles produced by the RCF mitigation measures all resulted in a concentrated hollow worn shape. According to Fröhling et al. [11] and Spangenberg et al. [6] such hollow worn shapes of the wheels in combination with worn rail profiles are more prone to RCF initiation. Rail Profile B resulted in the wear being spread more evenly across the tread, reducing the prevalence of false flanges, but at the same time increasing the probability of RCF initiation on the high rail of curves. The wear and RCF performance of two RCF mitigation measures are summarised in Table 3.

If the stiffness of the primary suspension is increased, the wheel wear will not be spread more across the tread. The long-term wear and RCF performance of bogies with stiffer primary suspension is unwanted. An increase in suspension stiffness is therefore ruled out as a RCF mitigation measure. 


\section{U. Spangenberg et al.}

The two rail profile designs proposed as a mitigation measure, both showed a reduced wheel wear life and an increased probability of initiating RCF on the rail surface. Such rail profiles will not be refined or pursued to establish a RCF management strategy for the iron ore line.

Both potential RCF mitigation measures are ineffective at spreading the wheel wear and reducing RCF initiation. Subsequently maintenance costs of wheels and rails will not be reduced by any of these RCF mitigation measures. The baseline arrangement showed that the current operating conditions on the iron ore line are better in terms of its wear and RCF performance compared with the two potential RCF mitigation measures. However, this baseline condition is still far from the optimum when RCF is concerned, since RCF is widespread on this line.

Table 3: Wear and RCF performance of RCF mitigation measures compared with the baseline arrangement

\begin{tabular}{|c|c|c|c|}
\hline $\begin{array}{l}\text { RCF mitigation } \\
\text { measure }\end{array}$ & Subcase & $\begin{array}{l}\text { Wear performance } \\
\text { (Wear rate) }\end{array}$ & RCF performance \\
\hline \multirow{3}{*}{$\begin{array}{l}\text { 1. Spread wheel } \\
\text { wear by increasing } \\
\text { suspension stiffness }\end{array}$} & 1.1. Stiffness $\mathrm{x} 1.5$ & Increased & - \\
\hline & 1.2. Stiffness $x 2$ & More severe & Worse \\
\hline & 1.3. Stiffness $x 5$ & Most severe & Much worse \\
\hline \multirow{2}{*}{$\begin{array}{l}\text { 2. Change in rail } \\
\text { profile design }\end{array}$} & 2.1. Profile A & Increased & Much worse \\
\hline & 2.2. Profile B & Increased & $\begin{array}{l}\text { Much worse with } \\
\text { RCF initiation } \\
\text { predicted }\end{array}$ \\
\hline
\end{tabular}

\section{RECOMMENDATIONS}

To reduce the occurrence and propagation of RCF cracks, more conformal wheel and rail profiles are required that would spread the wheel wear across its tread, reducing the adverse false flange contact conditions. However, since changes to the rail profile are expensive to implement, it is recommended that a conformal wheel profile should be developed. A reduction in the suspension stiffness could be considered, since it could reduce the risk of RCF initiation and will increase the wear life of the wheel. The stability of a bogie with decreased primary suspension stiffness must however be considered.

\section{ACKNOWLEDGEMENTS}

This research did not receive any specific grant from funding agencies in the public, commercial, or not-for-profit sectors.

\section{REFERENCES}

[1] International Heavy Haul Association (IHHA). (2001). Guidelines To Best Practices For Heavy Haul Railway Operations: Wheel and Rail Interface Issues. Virginia Beach: International Heavy Haul Association.

[2] Scheffel, H. (1978). Experience gained by South African Railways with the diagonally stabilised (cross-anchor) bogies having self-steering wheelsets. Heavy Haul Railways Conference, Perth, Western Australia, September 1978.

[3] Scheffel, H. (1974). A new design approach for railway vehicle suspension. Rail Int., 638: 638-651.

[4] Tournay, H.M. \& Mulder, J.M. (1996). The transition from the wear to the stress regime. Wear, 191: 107-112. 
[5] Fröhling, R.D., Ekberg, A. \& Kabo, E. (2008). The detrimental effects of hollow wear -field experiences and numerical simulations. Wear, 265: 1283-1291.

[6] Spangenberg, U., Fröhling, R.D. \& Els, P.S. (2016). Influence of wheel and rail profile shape on the initiation of rolling contact fatigue cracks at high axle loads. Vehicle System Dynamics: International Journal of Vehicle Mechanics and Mobility, 54:638-652.

[7] Dikshit, V., Clayton, P. \& Christensen, D. (1991). Investigation of rolling contact fatigue in a head-hardened rail. Wear, 144:89-102.

[8] Evans, J. \& Iwnicki, S.D. (2002). Vehicle Dynamics and the Wheel-Rail Interface. IMechE Seminar - Wheels on Rails - An update, Understanding and managing the Wheel/Rail Interface. London: IMechE. Available from: http:/e-space.mmu.ac.uk/espace/bitstream/2173/11370/1/vehicle\%20dynamics\%20wheel\%20rail\%20interface.pdf (Accessed: 1 July 2015).

[9] Fröhling, R.D. (2003). Vehicle/track interaction optimisation within Spoornet. In: System Dynamics and Long-Term Behaviour of Railway Vehicles, Track and Subgrade. Edited by Popp, K. and Schiehlen, W. Berlin: Springer, pages 17-34.

[10] Johnson, K.L. (1989). The strength of surfaces in rolling contact. Journal of Mechanical Engineering Science, 203: 151-163.

[11] Fröhling, R.D., Spangenberg, U. \& Hettasch, G. (2012). Wheel/rail contact geometry assessment to limit rolling contact fatigue initiation at high axle loads. Vehicle System Dynamics: International Journal of Vehicle Mechanics and Mobility, 50 (Suppl. 1): 319334.

[12] Karttunen, K., Kabo, E. \& Ekberg, A. (2014a). Numerical Assessment of the influence of worn wheel tread geometry on rail and wheel deterioration. Wear, 317: 77-91.

[13] Scheffel, H. (1976). Self-steering wheelsets will reduce wear and permit higher speeds. Railway Gazette International, December 1976:453-456.

[14] Shevtsov, I.Y. (2008). Wheel-Rail Interface Optimisation. Doctoral Dissertation. Delft: Delft University of Technology.

[15] Polach, O. (2011). Wheel profile design for target conicity and wide tread wear spreading. Wear, 2011:195-202.

[16] Stow, J., Bevan, A. and Burstow, M. (2011). Developing Effective, Evidence Based Control Measures for Rolling Contact Fatigue. Proceedings of the $9^{\text {th }}$ World Congress on Railway Research. Lille: France, 22-26 May 2011.

[17] Shevtsov, I.Y., Markine, V.L. \& Esveld, C. (2008). Design of railway wheel profile taking into account rolling contact fatigue and wear. Wear, 265: 1273-1282.

[18] Persson, I., Nilsson, R., Bik, U., Lundgren, M. \& Iwnicki, S.D. (2010). Use of a genetic algorithm to improve the rail profile on Stockholm Underground. Vehicle system dynamics, 48 (Supplement 1): 89-104.

[19] Iwnicki, S.D. (2009). The Effect of Profiles on Wheel and Rail Damage. International Journal of Vehicle Structures and Systems, 1(4): 99-104.

[20] Schöch, W. (2011). Recommendations for strategic rail maintenance in Europe - The application of anti-head check profiles and cyclic grinding. Rail Engineering International, Edition 2011, Number 1: 6-10.

[21] Ekberg, A. \& Kabo, E. (2002). Rolling contact fatigue of railway wheels and rails - an overview. Proceedings of Rolling Contact Fatigue: Applications and Development, Brescia, Italy, pp 5-26.

[22] Lewis, R. \& Olofsson, U. (2009). Chapter 2: Basic tribology of the wheel-rail contact. In Wheel-rail interface handbook. Edited by Lewis, R. and Olofsson, U. Cambridge: Woodhead Publishing Ltd., pages 34-57.

[23] Kimura, Y., Sekizawa, M. \& Nitanai, A. (2002). Wear and fatigue in rolling contact. Wear, 253:9-16.

[24] Tunna, J., Sinclair, J. \& Perez, J. (2007). A review of wheel wear and rolling contact fatigue. Proceedings of the Institute of Mechanical Engineers, Part F: Journal of Rail and Rapid Transit, 221: 271-289.

[25] Fröhling, R.D. (2002). Strategies to Control Wheel Profile Wear. Vehicle System Dynamics Supplement, 37:490-501.

[26] Tunna, J. \& Urban, C. (2009). A parametric study of the effects of freight vehicles on rolling contact fatigue of rail. Proceedings of the Institution of Mechanical Engineers, Part F: Journal of Rail and Rapid Transit, 223: 141-151.

[27] Dirks, B. \& Enblom, R. (2011). Prediction model for wheel profile wear and rolling contact fatigue. Wear, 271: 210-217.

[28] Karttunen, K., Kabo, E. \& Ekberg, A. (2014b). The influence of track geometry irregularities on rolling contact fatigue. Wear, 314: 78-86. 
[29] European Committee for Standardisation (2012). EN 13231-3:2012: Railway applications - Track - Acceptance of works - Part 3: Acceptance of reprofiling rails in track. Brussels: European Committee for Standardisation (CEN).

[30] Nia, S.H., Casanueva, C. \& Stichel, S. (2015). Prediction of RCF and wear evolution of iron-ore locomotive wheels. Wear, 338-339:62-72.

[31] Braghin, F., Bruni, S. \& Lewis, R. (2009). Chapter 6: Railway wheel wear. In Wheel-rail interface handbook. Edited by Lewis, R. and Olofsson, U. Cambridge: Woodhead Publishing Ltd., pages 172-210.

[32] Enblom, R. (2009). Deterioration mechanisms in the wheel-rail interface with focus on wear prediction: a literature review. Vehicle System Dynamics: International Journal of Vehicle Mechanics and Mobility, 47(6): 661-700.

[33] Enblom, R. \& Berg, M. (2005). Simulation of railway wheel profile development due to wear - influence of disc braking and contact environment. Wear, 258:1055-1063.

[34] Pombo, J., Ambrósio, J., Pereira, M., Lewis, R., Dwyer-Joyce, R., Ariaudo, C. and Kuka, N. (2011). Development of a wear prediction tool for steel railway wheels using three alternative wear functions. Wear, 271: 238:245.

[35] Kalker, J.J. (1991). Simulation of the development of a railway wheel profile through wear. Wear, 150: 355-365.

[36] Pearce, T.G. \& Sherratt, N.D. (1991). Prediction of wheel profile wear. Wear, 144: 343351.

[37] Zobory, I. (1997). Prediction of Wheel/Rail Profile Wear. Vehicle System Dynamics, 28: 221-259.

[38] Chudzikiewicz, A., Kik, W., Moelle, D. and Piotrowski, J. (1998). A survey of wear theories for wheel and rail, Internal paper ArgeCare, Berlin: ArgeCare.

[39] Ignesti, M., Malvezzi, M., Marini, L., Meli, E. and Rindi, A. (2012). Development of a wear model for the prediction of wheel and rail profile evolution in railway systems. Wear, 284-285: 1-17.

[40] Jendel, T. (2002). Prediction of wheel profile wear - comparisons with field measurements. Wear, 253:89-99.

[41] Jendel, T. \& Berg, M. (2002). Prediction of Wheel Profile Wear, Vehicle System Dynamics, 37: 502-513.

[42] Johansson, A. \& Andersson, C. (2005). Out-of-round railway wheels - a study of wheel polygonalization through simulation of three-dimensional wheel-rail interaction and wear. Vehicle System Dynamics, 43(8):539-559.

[43] Chang, C., Wang, C. and Li, L. (2010). A study of a numerical analysis method for the wheel-rail wear of a heavy-haul train. Proceedings of the Institute of Mechanical Engineers Part F: Journal of Rail and Rapid Transit, 224: 473-482.

[44] Bevan, A., Molyneux-Berry, P., Eickhoff, B. \& Burstow, M. (2013). Development and validation of a wheel wear and rolling contact fatigue damage model. Wear, 307:100-111.

[45] VI-Rail version 16.0.23615. Computer software. Marburg: VI-grade GmbH; 2014.

[46] Grassie, S.L. (2015). Traction, curving and surface damage of rails, Part 2: Rail damage. Proceedings of the Institute of Mechanical Engineers, Part F: Journal of Rail and Rapid Transit, 229(3):330-339.

[47] Ekberg, A., Kabo, E. \& Andersson, H. (2002). An engineering model for prediction of rolling contact fatigue of railway wheels. Fatigue \& Fracture of Engineering Materials \& Structures, 25: 899-909.

[48] Marutla, M.A., Mistry, K., Van Aardt, J.H.P. \& Mtetwa, C.Q. (2012). BBB0481 ver. 2 Manual for track maintenance. Johannesburg: Transnet Freight Rail.

[49] Magel, E. \& Kalousek, J. (2002). The application of contact mechanics to rail profile design and rail grinding. Wear, 253: 308-316. 